\title{
A STUDY ON THE ACTIVITIES IN LEISURE TIME OF 13-14 YEAR OLD STUDENTS
}

\author{
P. Dikova* \\ Department Heavy Athletics, Boxing, Fencing and Sport for All, Sector Sport for All, \\ National Sports Academy "Vassil Levski", Sofia, Bulgaria
}

\begin{abstract}
Nowadays the technical progress results in reduced physical activity, which, in combination with unhealthy nutrition and imbalanced proportions between work and rest time, affects negatively on physical and mental individual health. These factors are particularly revealed in childhood and adolescence, for which high physical activity was distinctive in the past years. The most effective way to counteract to this is through active physical exercises and sports.

The present study analyzes the activities that 13-14 year old students are engaged in their leisure time. A total of 128 girls and 124 boys were interviewed, and the questions related to their leisure activities and their involvement in sports activities.

The analysis of the data from the conducted survey revealed the increased interest in sports activities of a large number of the persons studied. The activities they are engaged in their leisure time are quite diverse, which requires good prioritization, organization, motivation and self-discipline.
\end{abstract}

Key words: physical activity, lifestyle, adolescents, organization, self-discipline, motivation

\section{INTRODUCTION}

We live in a time of high technologies and computerization of a huge part of human activities. This progress is an example of the ever-increasing possibilities of facilitating a person's occupational and personal activities, but at the same time leads to reduced physical activity, which, in combination with unhealthy nutrition and impaired proportions between work and rest time, negatively affects the physical and mental health $(1,2)$. These factors are particularly expressed in childhood and adolescence, characterized by high physical activity in times past. In their leisure time, children and adolescents played in the yard, cycling and rollerblading, practicing sports, going out in the mountains, etc. It was in the fundament of their healthy growth, to deal more easily with viral diseases, to successfully accomplish their tasks at school $(3,4)$. Now

\footnotetext{
*Correspondence to: Petia Dikova, National Sports Academy "Vassil Levski”, Department Heavy athletics, boxing, fencing and sport for all, Sector Sport for all, 1700, Sofia, Bulgaria, Studentski grad, 21, Acad. Stefan Mladenov str., Email: petiamilanova@gmail.com, GSM: $+359893396470$
}

the percentage of children and adolescents with spinal distortions, hypertension, diabetes, obesity and more is growing tremendously. These diseases are provoked by the effects of number of factors, some related to the individual's behavior and attitude to his own health (5). The most direct and effective way to counteract this is through active physical exercises and sports $(6,7)$.

\section{METHODS}

How and what are doing in their leisure time 13-14-year-old boys and girls is the subject of the present study. The study has 128 girls and 124 boys as respondents. The questions they answered are related to their leisure activities and their commitment to sports activities.

The questionnaire contained the following questions:

1. What are you doing during your leisure time?

a) I play on the computer, tablet, surf the internet; b) I read books; c) I'm watching TV; d) I am listening to music; e) I'm going out with friends; f) I play sports; g) I help my parents at home; h) I'm playing with friends outside; i) other 
2. Do you attend in any additional courses (mathematics, Bulgarian language, literature...) in extracurricular time a) Yes; b) No;

3. What do you think is typical for your daily life?

a) I study too much; b) I play a lot of sports; c) I don't have time to meet my friends; d) I'm sitting in front of TV or PC; e) I eat all day; f) I don't play sports; g) other

4. Do you practice any sports in extracurricular time? a) Yes; b) No

5. In the last year have you participated in sports competitions? a) Yes; b) No. The data from the questionnaires were subjected to mathematical and statistical processing.

\section{RESULTS}

DIKOVA P.

Analyzed answers to the question "What are you doing during your leisure time?" (Figure 1) helps to understand the preferences of 13-14year-old boys and girls to fulfil in their leisure time with various activities. The overall view reveals that over $1 / 3$ of 13 -year-old and almost half of 14-year-old boys spend their time with computer games and surfing the Internet. A number of studies have proven that the childhood psyche has been harmed by communicating excessive time with a computer, tablet and mobile phone. Not all parents manage to control the sites their children visit, and in rare cases we are witnesses of the "education" that the internet provides them. We are aware that the internet is a part of young people's lives, but we are against its excessive use for entertainment purposes.

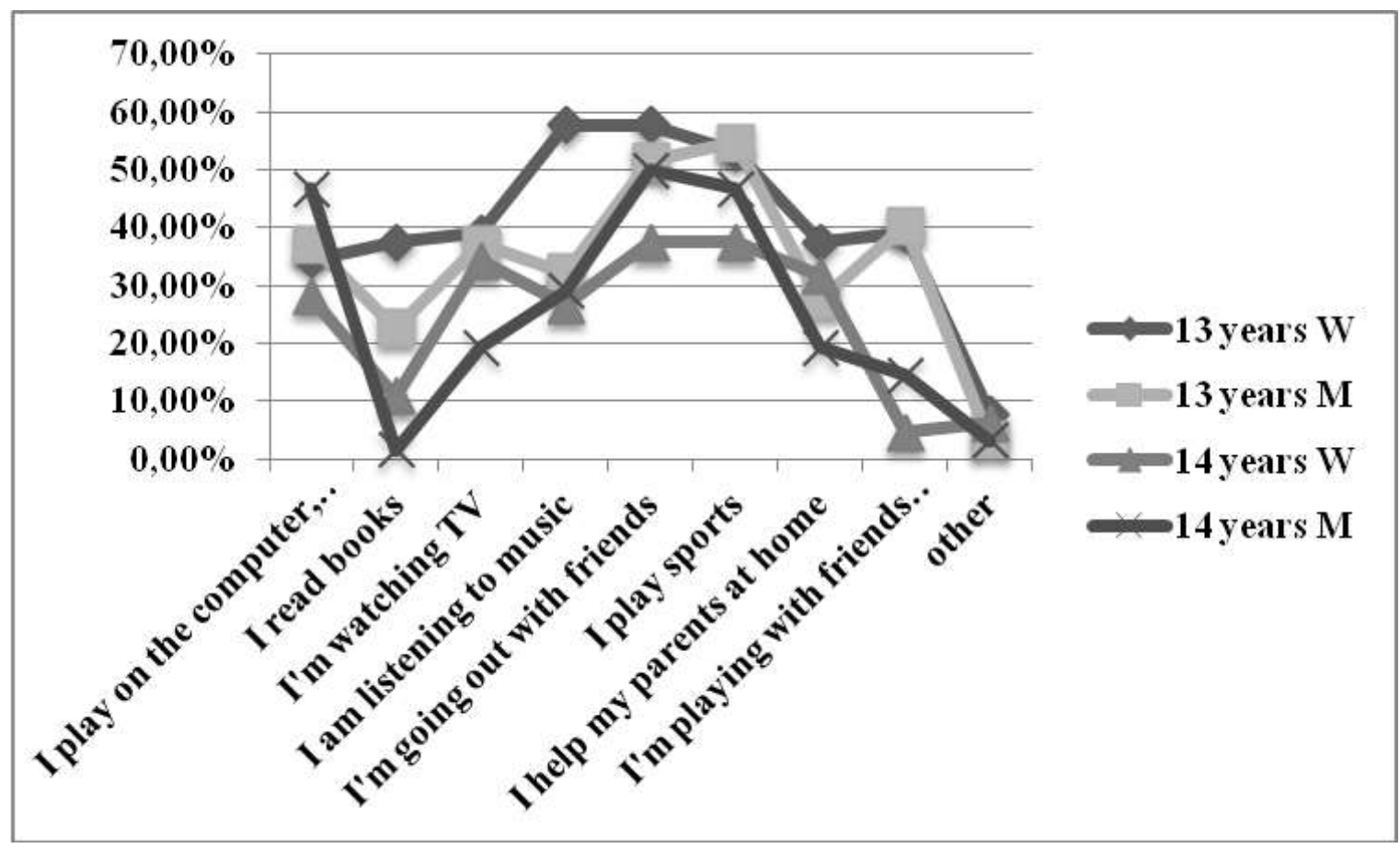

Figure 1. Answers to the question „What are you doing during your leisure time?”

Reading books is the most preferred activity for 13-year-old girls $(37.5 \%)$. Of the total aggregation surveyed, $22-23 \%$ of boys claim they read books. Nevertheless, there is a single case in one of the schools where only 1 boy indicated this answer. For 14-year-old, the reading rate drops dramatically $(10.9 \%$ for girls and $1.6 \%$ for boys). Watching television is $34-39 \%$ of the respondents in consuming their rest time. TV watching is the most unpopular activity among 14-year-old boys (19.3\%). Listening to music is emerging as one of the leading leisure activities for $57.8 \%$ of the girls and $32.3 \%$ of the 13-year-old boys, and below $1 / 3$ for 14 -year-old.
Meetings with friends outside and sports activities are preferred by almost half of the surveyed, with the exception of 14-year-old girls. Children are not seriously engaged in activities that help parents with home daily engagements. Particularly low is the percentage of 14-year-old children who help at home $-15.6 \%$ for girls and $19.3 \%$ for boys. Playing with friends outside is preferred by 39 $40 \%$ of 13-year-old children, while from 14year-old children, $14.5 \%$ of boys and only $4.7 \%$ of girls are interested in this activity.

Additional educational courses take a significant part in the lives of our 13-14-year- 
old respondents, which is a conclusion, based on the answers to the question "Do you attend in any additional courses (mathematics, Bulgarian language, literature...) in extracurricular time?" (Figure 2). From the analyzed positions of the answer "YES", we find out that courses in English, Bulgarian language and literature, mathematics, singing and drawing are mainly attended. Most likely, this is not much related to the gaps that lead to learning delays, but to the preparation for the
DIKOVA P. upcoming matriculation exams and applying to different schools after 7th grade. The high percentage of 14-year-old boys whether the negative answer is probably due to complex reasons - lack of interest, lack of ambition, the financial failure of parents, etc. A possible reason is the advent of puberty, one of the hallmarks of which is negation, rebellion and disregard for the opinion of both parents and teachers.

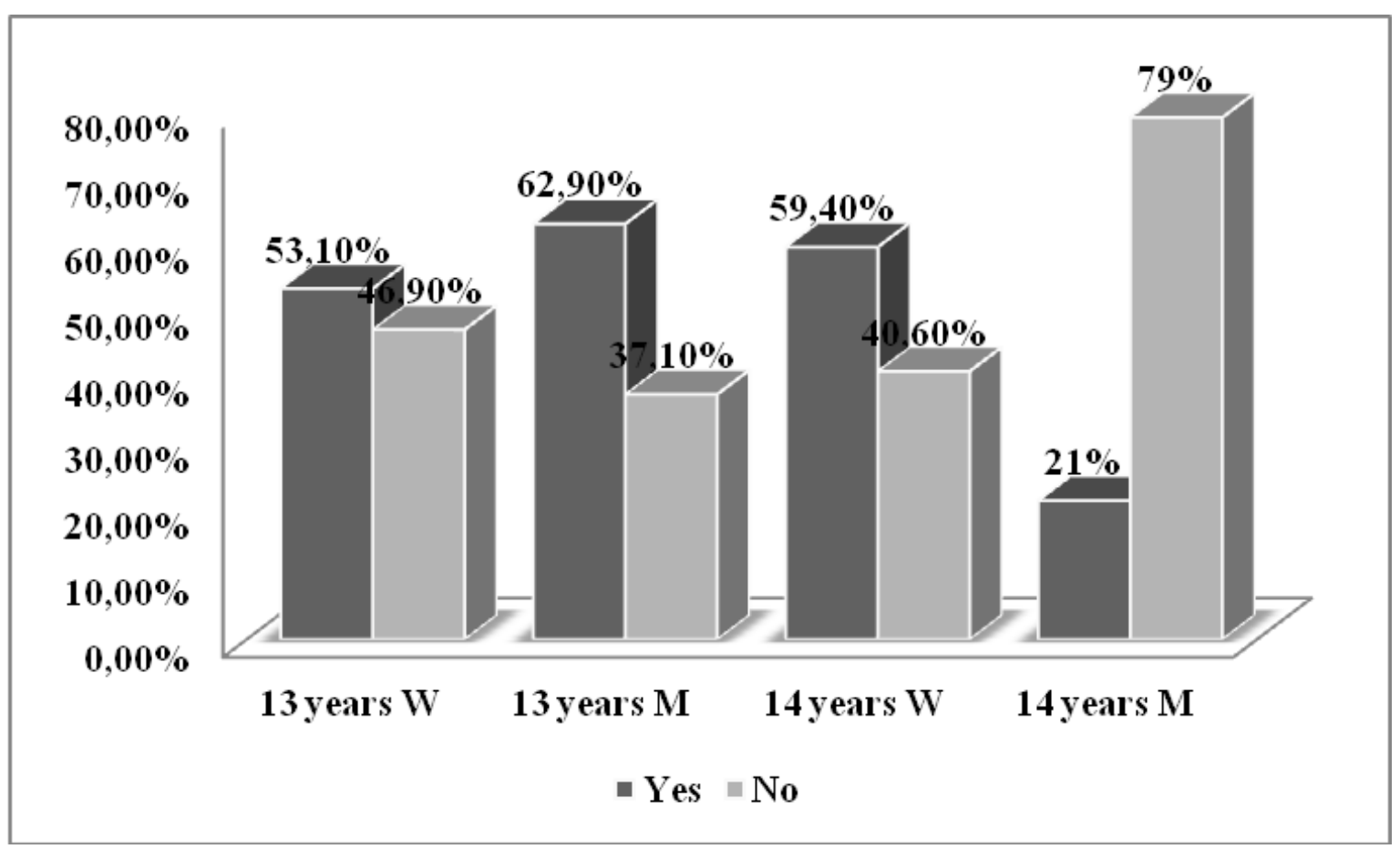

Figure 2. Gender and age distribution of the answers to the question: "Do you attend to any extra courses in extracurricular time?"

Lifestyle is determined by working and resting conditions, material and living conditions, the degree of physical activity, the high level of urbanization, the educational and cultural level, nutrition habits, etc. In most cases, these components act simultaneously, in interrelation, and as a result improve or impair the quality of life on one hand and the state of physical development and fitness on the other. It was interesting for us to find out what are the main dominants in the daily lives of 13-14year-old boys and girls. Answers of the question: "What do you think is typical for your daily life?" give us information about the type and nature of the activities they prefer to engage in. Just fewer than $30 \%$ of girls and
$20 \%$ of boys answered "I study too much". The most distinctive activity of all persons surveyed is sports $-63.7 \%$ of boys and $46.9 \%$ of girls practice different types of sports. Engaged in various types of activities are $29.7 \%$ of girls answered "I don't have time to meet my friends". One group of both sexes is emerging, characterized by inaction approximately $20 \%$ "sitting in front of the TV or computer", "eat all day", answered $17.2 \%$ of the girls and $13.7 \%$ of the boys. Those that are not practicing sports are $15.6 \%$ of girls and $8.1 \%$ of boys. As "other", $8.6 \%$ of girls and $3.2 \%$ of boys answered "I go outside to walk the dog" (Figure 3). 
DIKOVA P.

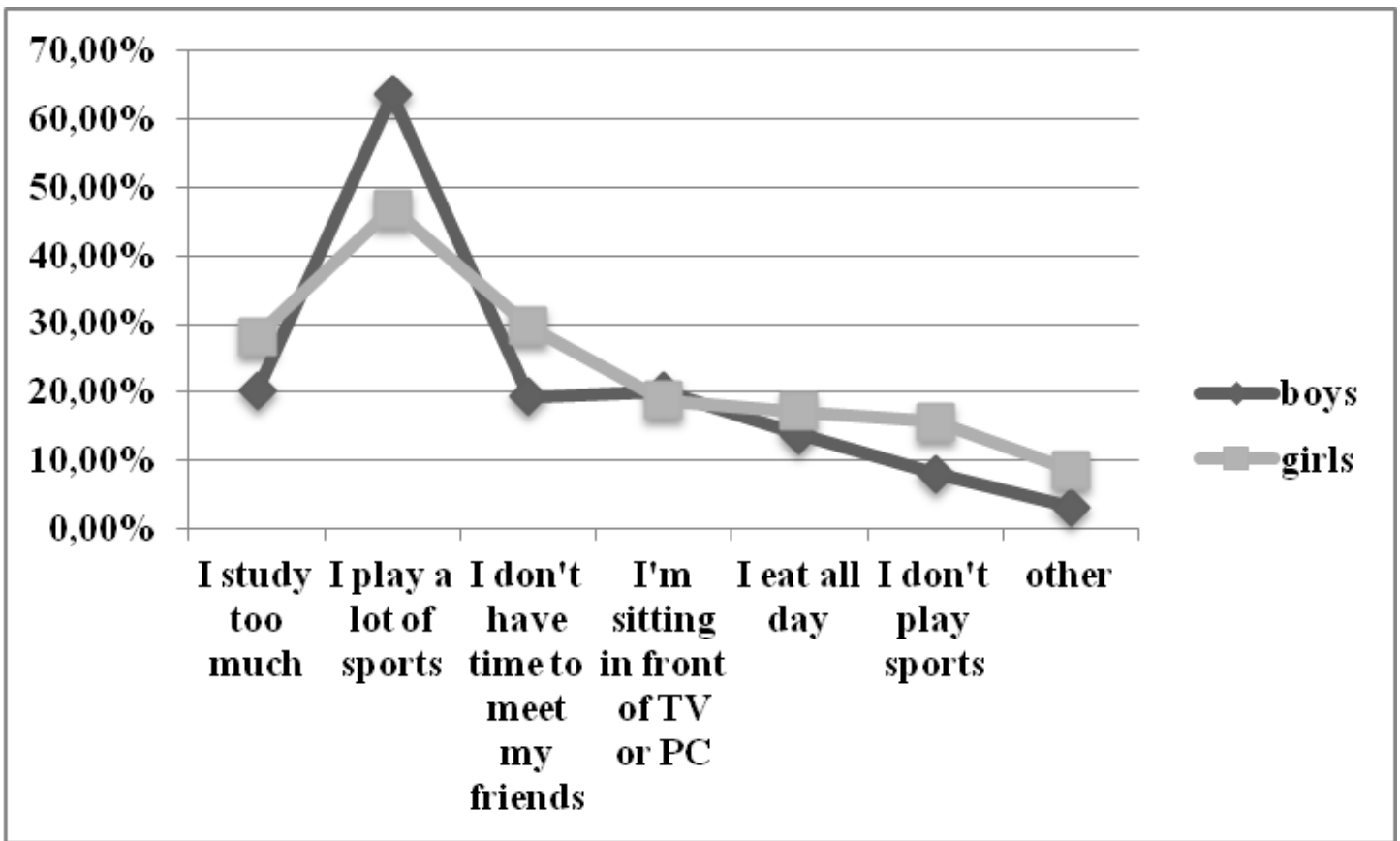

Figure 3. Percentage distribution of answers to the question "What do you think is typical for your daily life?"

A large part of them are united around the daily practice of some sport $(63.7 \%$ of boys and $46.9 \%$ of girls), learning is a priority for more than $1 / 4$ of the respondents.

From the stated so far, it is clear that the students surveyed have a positive attitude towards sports activities. The answers to the question: "Do you practice any sports in extracurricular time?" reveal a wide variety of sports. The girls have preferences to swimming training, sports dancing, basketball, rhythmic gymnastics, athletics, folk dance, karate, tennis and boys for football, athletics, volleyball, basketball, rugby, table tennis and kick-boxing. For 13-year-old boys and girls, the data indicate almost the same percentages of positive and negative responses. The number of 14-year-old boys actively involved in sports is quite high - 55 out of 62 for this age (Figure 4). Overall for the study group of 13-14-yearolds, the engagements with sports in extracurricular times are relatively good, but girls are lagging behind on this indicator.

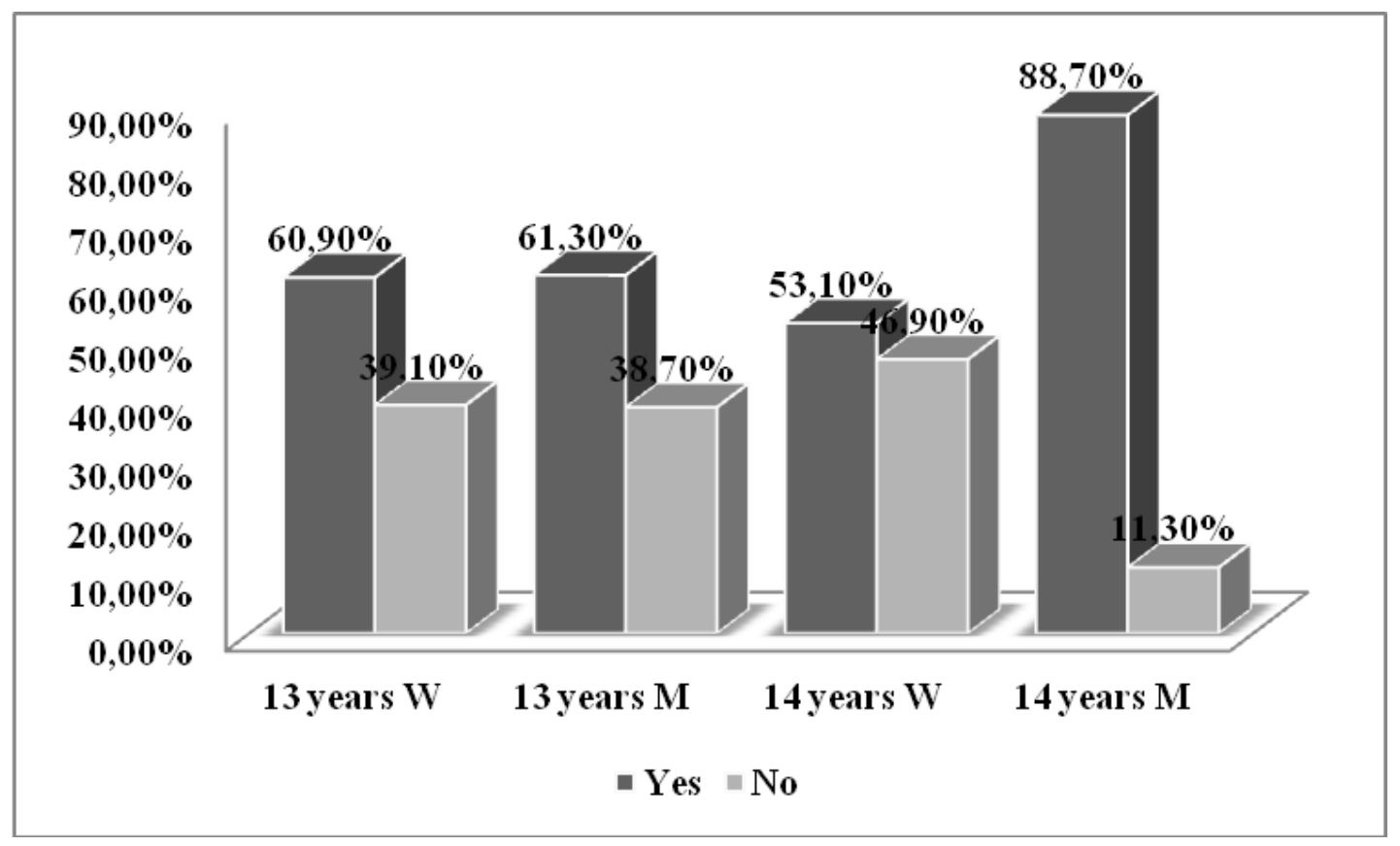

Figure 4. Distribution by gender and age of outdoor sports activities in extracurricular time 
We can consider the results of the answers to this question as satisfactory. This is a fertile age for the formation of physical skills and habits, for the cultivation of love of sports, for building of necessity of physical activity. All this is a key to better health and mental stability in the coming years of the growth process.

In childhood and adolescence, the competitive element is presenting in all activities performed. Everyone wants to be appreciated and encouraged. One of the main characteristics of sports activities is competition. It shows the degree of physical, technical and psychological preparation achieved. The analysis of the answers given to the question: "In the last year have you participated in sports competitions?" reveals that there is almost no difference in the sport competition events of 13-year-old boys and girls. The positive answer gave $56 \%$ of the girls at 14-year-old age. Their coevals are extremely active, of which very few (16.1\%) have no affinity for active sports-racing (Figure 5).

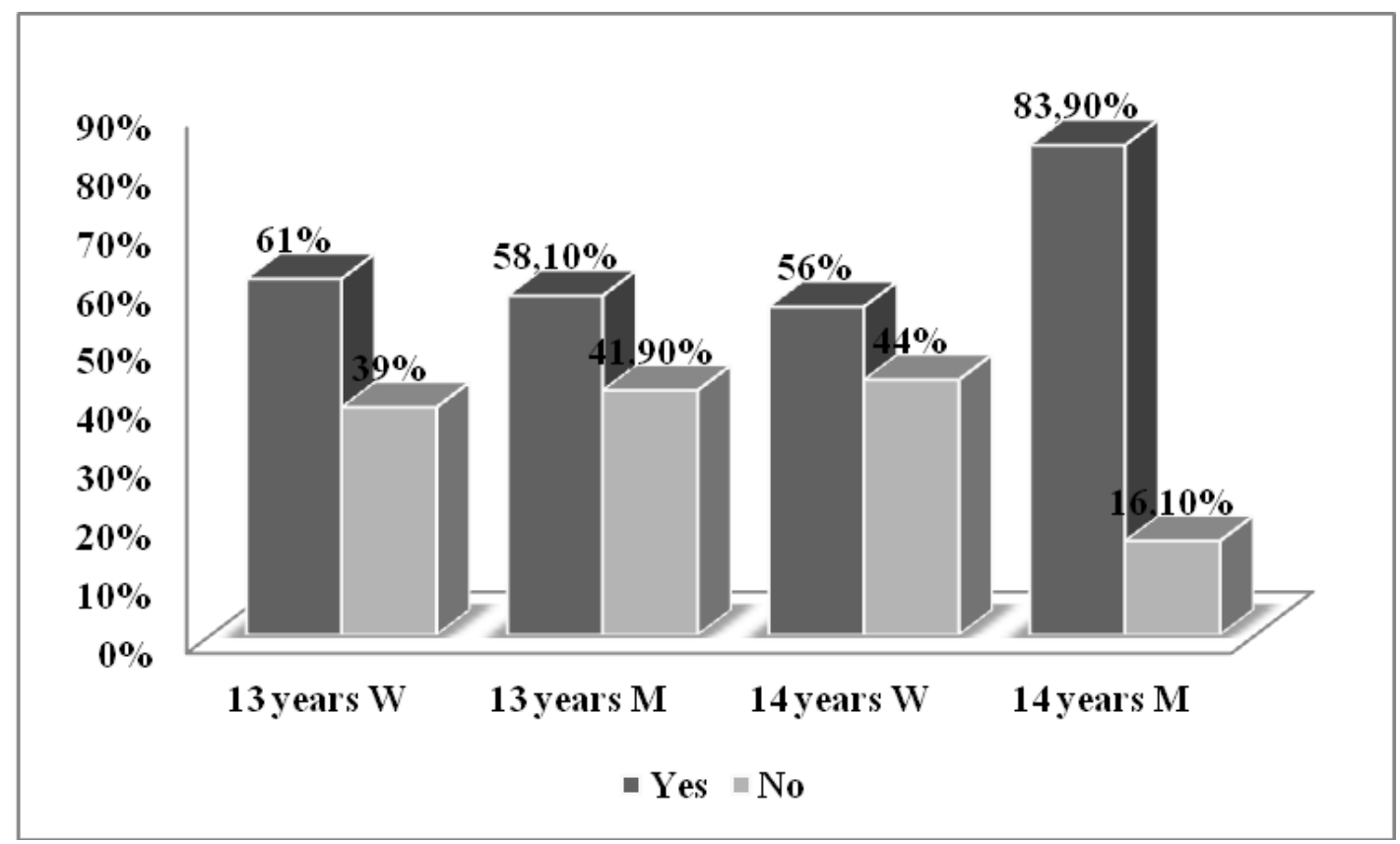

Figure. 5. Distributed answers to the question: "In the last year have you participated in sports competitions?"

More than half of the students surveyed participated on average in 6 sports competitions, with the exception of those who practice football, basketball and volleyball. In these sports games reach up to 30 during the year. These answers correspond to the answers to the previous question and illustrate the attitude of 13-14-year-old students to active sports activities. For this interest and desire for purposeful sports activities, we believe that family and school have major merit. The role of physical education and sport teachers, as well as coaches in the various sports, is extremely important. With their professionalism, knowledge and skills to work with children and adolescents, they form the basis for the formation of the core value at this age, namely: "a healthy spirit in a healthy body".

\section{CONCLUSIONS}

The analysis of the survey data among 13-14year-old boys and girls, related to types of activities that utilize their leisure time revealed an increased interest of many of them in sports activities. The lack of established reading habits is alarming, with the desperate situation for 14-year-old children. Only $1.6 \%$ of boys and $10.9 \%$ of girls reported reading books during their leisure time. More than half of the study group, with the exception of 14-year-old boys, attends additional educational courses, which helps to fill gaps in their main subjects, considering the upcoming matriculation exams in $7^{\text {th }}$ grade.

The activities they are engaged in in their leisure time the respondent are very diversified, which requires good prioritization, organization, motivation and self-discipline. 


\section{REFERENCES}

1. Chonova, R., Ganeva, V, Adolescents' pastimes in the new information environment. Scientific papers of Ruse University. Vol. 47, Series 5.2, pp. 94-98, 2008.

2. Milanova, P., Lifestyle and health status of adolescents. Dissertation, S., 2012.

3. Boyadjieva, N., Children and free time. Pedagogy, 9/2002.

4. Popov, L., Pedagogical aspects of free time, S., 2010.

5. Miloshova, E., Healthy lifestyle - a survey among young Bulgarians. Proceeding book of the International Congress "Applied Sports Sciences” Sofia, pp. 288-291, 2017.

6. Dikova, P., A study of the motor fitness of students aged 12-13. International Congress of Applied Sports Science. Balkan Scientific Congress Physical Education, Sport, Health 15-16 November 2019. Proceeding book. p. 418-422, 2019.

7. Janssen, I., Leblanc A.G., Systematic review of the health benefits of physical activity and fitness in school-aged children and youth. International Journal of Behavioral Nutrition and Physical Activity, 2010. 